\title{
PERFORMANCE OF SELECTED COCONUT VARIETIES/ HYBRIDS UNDER SEQUENTIAL COCONUT TODDY AND NUT PRODUCTION SCHEME OR SCTNP ${ }^{1}$
}

\author{
M.I. Secretaria ${ }^{2}$, R.M. Ebuna ${ }^{3}$, S.S. Magat ${ }^{4}$, J.N. Maravilla ${ }^{2}$, \\ G.A. Santos ${ }^{3}$ and G.B. Baylon ${ }^{3}$
}

\begin{abstract}
A B S T R A C T
The response to sequential coconut toddy and nut production (SCTNP) scheme of four coconut varieties/hybrids at PCAZamboanga Research Center, San Ramon, Zamboanga City showed that the dwarf $x$ tall hybrids, Malayan red dwarf $x$ Baybay tall (MRD $x$ BAYT), Malayan red dwarf $x$ Tagnanan tall (MRD $x$ TAGT) and Catigan green dwarf $x$ Laguna tall (CATD $x$ LAGT) produced significantly higher toddy (495 - 699 li/tree/yr) and nut yield (143169 nuts/tree/yr) compared to tall cultivar, 'Laguna' LAGT (364 li and 123 nuts per tree per year). Varietal difference in terms of the floral and vegetative characteristics of the coconut cultivar and hybrids contributed significantly to the differences in the sap/toddy and nut yields.

Keywords: Coconut hybrid, coconut toddy, sap by-products, sequential Coconut toddy and nut production, SCTNP \footnotetext{
Dialogue with Industry Sectors, August 22, 2001. Philippine Coconut Authority Diliman, Quezon City.

${ }^{2}$ PCA-Davao Research Center, Bago Oshiro, Davao City, e-mail: pcadrc@interasia.com.ph

${ }^{3}$ PCA-Zamboanga Research Center, San Ramon, Zamboanga City, e-mail: wesmarrdec@wmsu.edu.ph sevmagat@mozcom.com
}

${ }^{1}$ Paper presented during the CocoWeek $R \& D$ Symposium cum Consultative

${ }^{4}$ PCA-Research and Development Branch, Diliman, Quezon City, e-mail:
\end{abstract}


Based on one year and eight months production period, the SCTNP palms with toddy and nut yields produced an average annual net return of $P 246,705$, ten times that of the net returns from the common practice or of nut production (NP) palms $(P 23,855)\{1 \$$ $=P 51\}$ with nut/copra yield alone. The SCTNP palms also manifested higher benefit-cost ratio over the NP palms with 1.83 and 1.00, respectively. Between local hybrids and tall variety, the dwarf $x$ tall hybrids are highly recommended materials for SCTNP scheme as reflected in their higher net returns and benefit-cost ratio over the latter.

The processing of coconut toddy into its by-products (beverage, syrup, sugar and vinegar) offers a bigger opportunity for coconut farmers for increased income due to higher net returns derived from production and marketing of these products. The SCTNP allows coconut farms to follow an integrated production, processing and marketing enterprise, aimed at optimizing farmer's income.

\section{Introduction}

Research efforts had been conducted in the past decade to generate significant and appropriate technologies with the aim of increasing farmer's income and sustained coconut productivity. Along this line, promising local coconut hybrids and cultivars were developed by the Philippine Coconut Authority (PCA) and were recommended for the National Planting/Replanting Program and Small Coconut Farms Development Program (SCFDP) of the government. These materials will ultimately replace large areas of senile and low - producing coconut palms in most of the coconut growing regions. Initially in 1989, four types of planting materials were developed and recommended by the Authority namely, Catigan $x$ Laguna (CATD x LAGT- PCA 15-1), Malayan red dwarf $x$ 
Tagnanan tall (MRD x TAGT - PCA 15-2) MRD x Baybay tall ( MRD x BAYT - PCA 15-3) and BAYT for the implementation of the SCFDP by PCA.

Likewise, highly efficient and cost-effective production scheme/technologies were developed to improve and sustain farm productivity. One of the potential and practical production schemes that could alleviate farmers' income is coconut toddy and nut/copra production in one inflorescence or spadix. Known as 'Sequential coconut toddy and nut production' (SCTNP) scheme which was conceptualized by Magat in late 80's and developed by Maravilla and Magat (1991), the technology provides income to coconut farmers while the inflorescence is still close and female flowers are still developing. This scheme has been successfully done in 'Laguna' tall and Malayan yellow dwarf $\mathrm{x}$ West African tall ('MAWA') hybrid coconuts and proved feasible and profitable (Maravilla and Magat, 1993). But how about the local hybrids and which are the best for the SCTNP scheme? These inquiries led to the conduct of this current research work.

With the current trend on integrated production management system for production sustainability and enhancement of management of our renewable natural resources on promising coconut hybrids and cultivars, it was worthwhile conducting the above mentioned scheme on promising coconut varieties and hybrids, some of which are presently used in the replanting/new planting program of the government. In addition to this, an integrated production management system approach up to post production aspect involving small coconut farms maybe a good means of helping our poor coconut farmers in the upliftment of their lives, through higher farm incomes.

This paper presents the performance of selected coconut varieties and hybrids planted at the PCA-Zamboanga Research Center, San Ramon, Zamboanga City under the SCTNP scheme 
plus the simple processing of harvested coconut sap into high value products.

\section{Materials and methods}

Phase 1 (April -December, 1997):

1) Catigan dwarf $x$ Laguna tall hybrid - CATD x LAGT (PCA 15-1)

2) Malayan red dwarf $x$ Tagnanan tall hybrid - MRD x TAGT (PCA 15-2)

3) Malayan red dwarf $x$ Baybay tall hybrid - MRD x BAYT (PCA 15-3)

4) 'Laguna'tall variety ${ }^{5}$

5) CATD x CATD hybrid

6) Tacunan dwarf (TACD)

Phase 2 (April, 1999 to December 2000):

1) CATD X LAGT hybrid

2) MRD x TAGT hybrid

3) MRD x BAYT hybrid

4) LAGT variety

The palms aged 18-19 years old were planted at the PCAZamboanga Research Center, San Ramon, Zamboanga City located $22 \mathrm{kms}$ from city proper, the center being situated 3-6 meters above sea level. The site is flat and fairly well drained. It has an average annual rainfall (from 1997-2000) of $1662 \mathrm{~mm}$ and water deficit occurrence ranging from -42.5 to $-113 \mathrm{~mm}$ during the months of April to December, 1997.

5 located at ZRC and on-farm site at Sinubung, Zamboanga City, Western Mindanao 
The palms were planted at a distance of $9 \mathrm{~m} \times 9 \mathrm{~m}$ triangular system. The experimental design used was completely randomized design (CRD) with 3 replicates. Eight palms per plot per hybrid/variety were used for tapping.

The SCTNP scheme developed by Maravilla and Magat (1993) was used for tapping the palms. This involves the tapping of the first half of the spadix for sap or 'tuba' and allowing the remaining half to develop normally to produce either the 8-month 'buko'or matured 12-month nut. The diagram of different stages of SCTNP (Maravilla and Magat, 1993) is illustrated below:

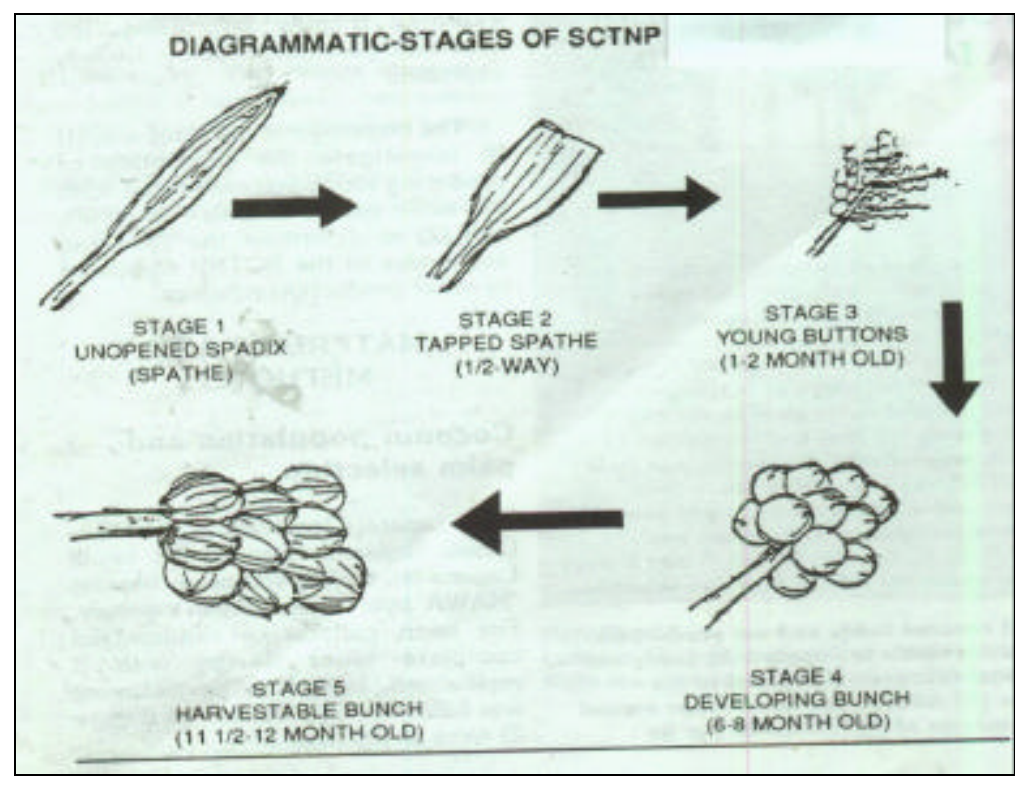


Data on nut/copra and toddy were gathered from 8 palms. However, another 8 palms per replicate of each variety and hybrid were also observed for sole nut and copra production to compare their yield with the SCTNP palms. Toddy yield was collected daily. A portion of toddy produced was processed into several coconut sap byproducts such as fresh cooled sap drink, vinegar, syrup and sugar.

\section{Results and Discussion}

\section{Toddy yield as affected by SCTNP scheme}

Phase 1:

On the first month of tapping, no significant differences in toddy yield was observed among the six coconut populations (Fig. 1). However, on the second month, significant differences in sap yield per month was observed. 'Laguna' tall yielded the highest volume followed by the dwarf $\mathrm{x}$ tall hybrids, CATD $\mathrm{x}$ LAGT, MRD $\mathrm{x}$ TAGT, MRD x BAYT. TACD had the lowest which was comparable to CATD $x$ CATD . From the $3^{\text {rd }}$ to $7^{\text {th }}$ month of tapping, an evident significant varietal difference on the response of coconut populations to SCTNP in terms of toddy yield per tree was noted. A locally produced $\mathrm{d} x \mathrm{t}$ hybrid, MRD x BAYT known as PCA 15-3 showed potential as a source of coconut toddy as indicated in the consistently higher sap yield in most of the months. Similarly, the other two $\mathrm{d} x$ t hybrid and a local tall cultivar gave higher toddy yield compared to the $\mathrm{d} x \mathrm{~d}$ hybrid (CATD x CATD) and dwarf cultivar (TACD). Since TACD barely produced toddy, tapping was stopped on the six month.

Based on the initial results on toddy production of the six coconut populations, only four (3 local hybrids and one tall cultivar) were used as experimental materials for this performance evaluation under the SCTNP scheme. 


\section{Phase 2:}

Initial tapping of experimental palms was undertaken on the April, 1999 and consequently toddy production was noted one month after. A statistically significant difference on toddy yield for 8 months (May to Dec, 1999) was observed among the varietal treatments (Table 1). The coconut hybrids produced significantly bigger volume of toddy than the tall 'LAGT' variety. The hybrid MRD x TAGT produced the highest toddy yield, followed by hybrid MRD $x$ BAYT, CATD $x$ LAGT and LAGT with the least volume of toddy yield .

As of December 30,1999, the highest number of palms with toddy production was observed in hybrid MRD x TAGT with 23 palms followed by hybrids CATD x LAGT, MRD x BAYT and LAGT with 21, 20 and 14 palms, respectively.

On the second year, a significant effect of varietal treatment on the average monthly toddy yield per tree was again noted. The hybrid MRD x BAYT produced significantly the highest toddy yield (90 li/tree/mo) in most of the months of the year (Table 2). It was followed by CATD x LAGT, MRD x TAGT and LAGT with the least volume of toddy yield (Fig. 2).

\section{Factors affecting differences in toddy yield}

Several factors such as age of palms and climate (Browning, 1961), phenotypic yield group (Maravilla, 1975) and mineral nutrition of palms (Maravilla and Magat, 1993) are some of the reasons for the observed differences in toddy yield of coconut palms. In this particular study, a specific factor could be cited as a significant contributory to the differences in coconut toddy, i.e. varietal difference in terms of vegetative and floral characteristics of the coconut palms. Observed significant differences in the leaf production and number of living fronds and the number of spathe 
produced and its structure (circumference and length) have contributed to the differences in sap yield of coconut hybrids and cultivars (Table 3). Further examination of the effect of these characters could be indicated by the correlation coefficients between sap yield and these characters ( Table 4).

Based on the correlation coefficient values and their significance, it appeared that the floral structure particularly the length of the spadix is a good indicator for high sap yielding coconut palm because of the positive and significant correlation coefficient value between sap yield and spadix length in terms of over-all coconut populations. Longer spathe implies longer spikelets and flowers which are contained inside the spathe and could be the source of sap from the spathe. This could be well supported with observations made by Santos and Balingasa (1977) on the inflorescence component characters of some local tall and dwarf cultivars where TAGT (one of the parent material of the hybrid used in SCTNP) had the most number and longest spikelets followed by LAGT and CATD. These two cultivars were also noted to have more buttons (female flowers) than TACD which had the shortest spikelets and fewer button count and subsequently lesser weight of fresh flowers. This clearly explained why the hybrids with TAGT, LAGT and CATD parents had better toddy yield that the local dwarf cultivar, TACD which had inferior floral structure. Figure 3 clearly demonstrates the volume of spikelets and female flowers contained inside the spadices of the six coconut populations initially used for SCTNP scheme. The upper portion of the mark in the middle of the spathe represents the area where tapping was done in this floral structure.

As to the vegetative characters, the number of living fronds appeared to be a better index than number of leaves produced as to the potential of coconut palm to produce more toddy due to its significant correlation among coconut populations particularly in 
CAT $x$ LAGT hybrid. This indicates that palms which have more living fronds have the tendency to have more toddy yield, simply because every living frond of bearing palms has a natural capacity to support a spathe which can be used for tapping (coconut sap harvesting).

\section{Nut production of SCTNP and NP palms}

For palms observed for nut production only( Fig 4a), a significant effect of varietal treatments was manifested on the annual number of nuts and copra weight per palm (Table 5) on the first year. The three coconut local hybrids showed statistically higher number of nuts and heavier copra weight per palm than LAGT cultivar. The CATD x LAGT produced statistically the highest number of nuts per palm. The same trend was observed for copra weight per palm of the four treatments. No significant effect was observed on copra weight per nut.

After one year of tapping, nut production from SCTNP palms (Fig. 4b) was noted. Similar to toddy yield of different coconut populations, nut yield per palm showed varietal difference both for NP and SCTNP palms (Table 6). Between NP and SCTNP palms, the former had higher nut and copra yield per palm than the latter. It could be observed that MRD x BAYT showed superiority among local hybrids in terms of its nut and copra yield per palm for SCTNP and NP palms when there was a month (March) that its yield was almost three times higher than the other coconut populations.

Based on the toddy and nut yields, it could be noted that among the coconut populations, hybrids MRD x BAYT, CATD $x$ LAGT and MRD x TAGT are highly recommended materials for SCTNP scheme indicating that local dwarf $x$ tall $(\mathrm{d} x \mathrm{t})$ hybrids are better coconut materials than local tall cultivar for such production scheme. The current coconut plantings of hybrids and talls $(132,000$ 
palms in 960 ha) under the nationwide MULTILOC ACTPRO site (18 provinces)under the PCA-DOST-PCARRD collaboration (1995 to date) are potential palms for SCTNP technology application of farmers (Table 7).

\section{$\underline{\text { Economic analysis }}$}

Cost and return analysis between SCTNP and NP palms (for a period of one year and eight months) of 3 local hybrids and one tall cultivar revealed higher net income from SCTNP palms than the NP palms in all coconut populations (Table 8). Although there was a decrease in nut and copra production in SCTNP palms, higher net income was realized due to the additional income toddy and products derived. For simplicity of analysis, toddy yield was sold as fresh toddy. However, processing of toddy into its by-products e.g. fresh sap drink, vinegar, syrup and sugar which command higher price could be done easily at village level with the procedures developed for such organically-produced food products.(PCA echno Guide Sheet No. 8 -'Producing high value "organic \& green" foods from coconut sap at village level', 2000).

Among the coconut populations, the $\mathrm{d} x \mathrm{t}$ hybrids: MRD $\mathrm{x}$ BAYT, MRD x TAGT and CATD x LAGT under SCTNP scheme yielded an average net income/ha/yr (based on 1.67 years of production ) of $\mathrm{P} 319,868 ; 280,923$ and 290,974, respectively compared with that of NP palms for the same hybrids: P33,180; 22,686 and 22,209. The 'LAGT'variety had the lowest average net income/ha/yr both under the SCTNP and NP schemes with P95,055 and $\mathrm{P} 17,344$, respectively.

Likewise, higher benefit-cost ratio (BCR) was realized under SCTNP scheme regardless of variety with 1.84 as compared to NP palms with 1.06 only. Between local $\mathrm{d} x \mathrm{t}$ hybrids and tall cultivar, the former had higher average net income/ha/yr and benefit-cost 
ratio (BCR) than the latter (P297,255 and 2.21 as against $\mathrm{P} 95,055$ and 0.71 ,respectively) indicating higher productivity of $\mathrm{d} x \mathrm{t}$ hybrids over the tall cultivar.

\section{Processing of coconut sap by-products}

The conversion of toddy into sap drink, coco nectar (syrup), sugar and vinegar involves a simple operation. As the coconut sap is highly perishable due to the yeast micro flora, the harvested sap should be immediately processed by boiling for $1 / 2$ hour in a large cast iron frying pan. Some significant results of the preliminary trials (at the SCTNP laboratory of PCA-ZRC) on the processing of coconut sap-based products are presented as follows:

1) Results of the acceptability or organoleptic test revealed that the coconut sap vinegar produced was highly acceptable, comparable or even better in acid taste with other commercial brands of vinegar.

2) Fresh sap drink was acceptable to male respondents as well as to female ones but should be taken in smaller amounts only. Like buko juice, fresh sap drink have a high potential in the market especially with the present trend of utilizing natural drinks. Both products (vinegar and fresh sap drink) requires a very simple procedure and equipment such as refrigerator and cooking facilities and materials (clean bottles, plastic cups etc.) which are normally present in a household.

3) Coconut syrup initially produced (with sour taste) for the production of sugar was further tested during the second phase of the project following the procedure indicated in the Techno Guide Sheet No. 8. To date, a better quality and acceptable coconut syrup and sugar have been produced from the SCTNP coconut sap by the project. 


\section{Summary and Conclusion}

1) Coconut varieties/hybrids responded differently to SCTNP scheme. Some promising coconut local $\mathrm{d} x \mathrm{t}$ hybrids such as MRD x TAGT, MRD x BAYT, CATD x LAGT consistently produced higher sap yield than local tall cultivar, LAGT.

2) Variation in the production of toddy and nut/copra yields under the SCTNP scheme can be attributed to varietal difference particularly in terms of the floral and vegetative structure of coconut palms, i.e. the spathe length and thickness and number of living fronds can be good indicators of high toddy yielding palms.

3) Sequential coconut toddy and nut production scheme realized a very satisfactory level of toddy and nut yield with average annual net income/ha/yr of P246,705 as against P23,855 for NP palms regardless of variety. Between $\mathrm{d} \times \mathrm{t}$ hybrids and tall variety, the former had higher annual net income/ha/yr and BCR than the latter. This confirms the higher productivity of $d$ $x t$ hybrids over tall cultivar when used for NP or SCTNP schemes.

4) Processing of coconut sap into some of its by-products e.g. vinegar, fresh toddy drink, syrup and sugar offers bigger opportunity for coconut farmers for increased income.

\section{Recommendations}

1) To achieve improved and sustained coconut farm productivity, it is best to explore the new idea of utilizing this new package of technologies, i.e SCTNP scheme in promising coconut local dwarf $\mathrm{x}$ tall hybrids and tall cultivars. 
2) Farmers should be encouraged to diversify their production to high value products (beverage, syrup, vinegar and sugar) from coconut toddy and mature nuts from the SCTNP scheme, producing fresh nut-based, copra-based, shell-based, coir-based high value products.

3) Further studies on the product quality and packaging of sapbased products should be highly encouraged.

4) In the application of the SCTNP scheme in coconut farms grown with local $\mathrm{d} \times \mathrm{t}$ hybrids and tall cultivars, the required success factors are:

a) Skilled labor for toddy production (toddy tapping)

b) Full-bearing productive palms with superior floral structure and produce inflorescence regularly and frequently

c) Suitable environmental conditions, including balanced nutrition of palms

d) Available market for toddy and its by-products

e) Adequate initial operating capital

f) Family labor involvement

\section{ACKNOWLEDGMENT}

With sincere appreciation and gratitude, the authors wish to expressed their heartfelt thanks to the following:

To the PCA Management, Former Administrators Virgilio M. David, Eduardo U. Escueta, Deputy Administrator Carlos B. Carpio and former Department Manager Romero C. Blancaver for endorsing 
this research project to the United Nations Agency for International Development (USAID) thru National Development and Economic Authority - Technical Resource Project (NEDA-TRP) and the Department of Agriculture- Bureau of Agricultural Researcth for the funding support of the Phase 1 and 2 of this research project, respectively and for the needed support during the conduct of the project;

To Mr. Rogaciano Z. Margate, Scientist III and Officer-incharge of PCA-Davao Research Center for his valuable support to the project;

To the PCA-Zamboanga Research Center former Department Manager, Rodolfo M. Madrazo, technical staff and field men who wholeheartedly supported in most of the activities of the project without them, this research undertaken may not be possible;

To Barangay Captain Ramon Soler of Sinubung, Zamboanga City who unselfishly provide us his support and his farm as site of the farmer's field;

To the rest who in their own and simple ways have shared their help in the conduct of the study; and

Above all, to our Almighty God, who is the source of our wisdom, knowledge and strength, without Him, we can do nothing.

\section{LITERATURE CITED}

Browning, K.C. and Symons, C.T. 1961. Coconut toddy in Ceylon. J. Soc. Chem.. Ind. 35:1138-1142. In. Child R. (Editor) Coconuts. Longman. London. 
Maravilla, J.N. 1975. Toddy-tapping, its effects on the yield of coconut, PCA-ARD. Annual Report 1974-75. pp. 9-11.

Maravilla, J.N. and S. S. Magat. 1991. Comparative response of hybrid and local tall coconut to nut-toddy production. In. Highlights '91. Published by the Phil. Council of Agriculture, Forestry and Natural Resources Research and Development (PCARRD), Dept. of Science and Technology. $159 \mathrm{p}$.

Maravilla, J.N. and Magat, S.S. 1993. Sequential coconut toddy-nut production (SCTNP) in 'Laguna' tall variety and hybrid coconut. Paper presented (Best Paper Session) at the $9^{\text {th }}$ Annual Scientific Meeting of the Federation of Crop Science Societies of the Philippines (FCSSP). Aklan State College of Agriculture, Aklan. May, 1993. Also In. Phil. Journal of Coconut Studies XVIII (2):715 .

Santos, G.A. and E.N. Balingasa. 1977. Observations on the inflorescence component characters and pollen of five coconut populations. In. Annual Report, 1977. Agricultural Research Branch. PCA - Diliman, Quezon City. pp.9-15.

Techno Guide Sheet No. 8. 2000. Producing high value organic and green" foods from coconut sap at village level. Pamphlet produced by PCA-ARDB, DRC and ZRC . 
Fig.1.Toddy yield per tree (li) per month of 6 coconut populations at PCA-ZRC, 1997

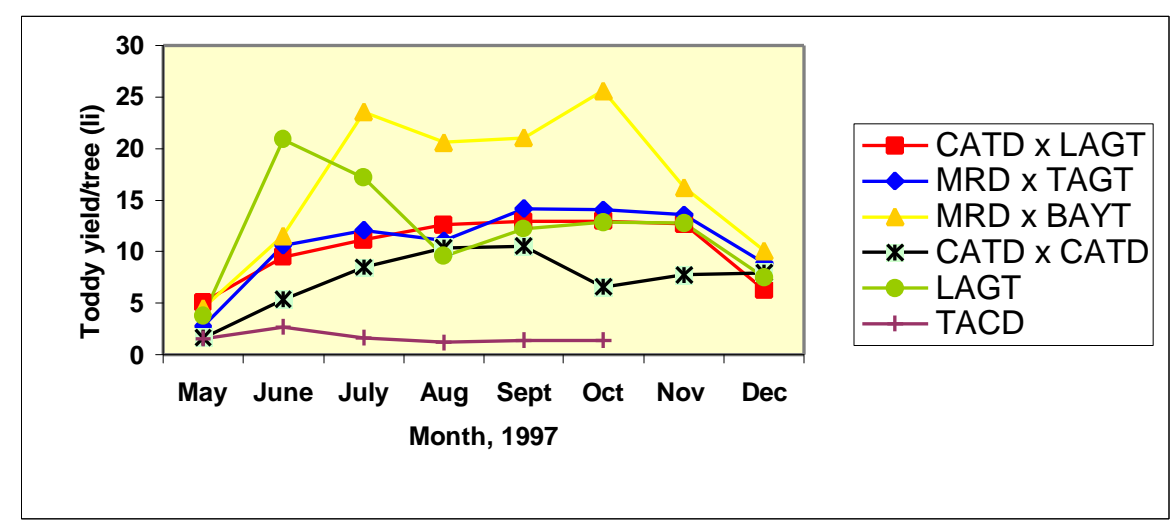




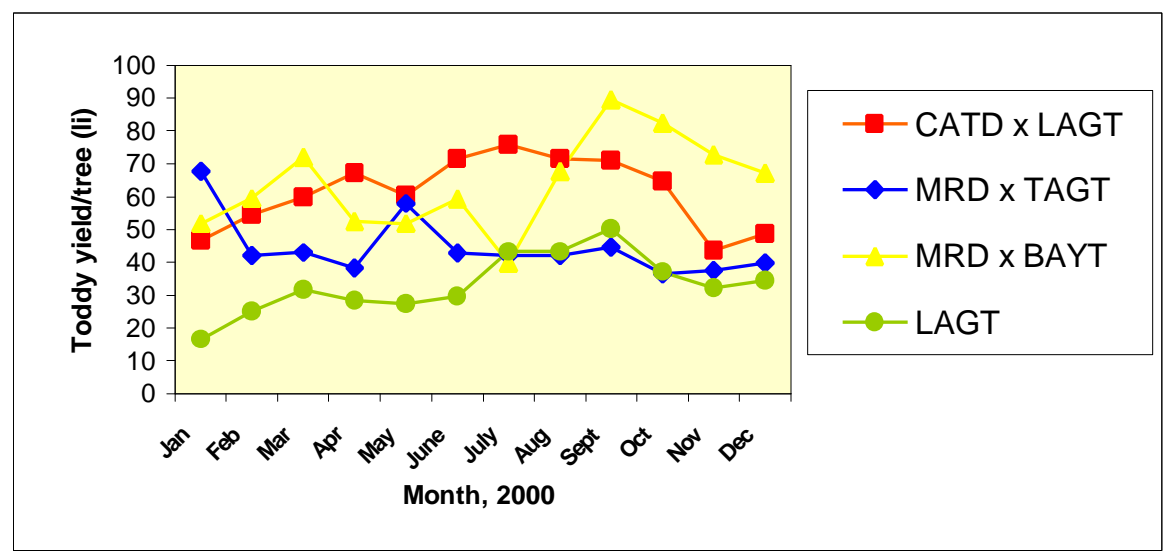

Fig. 2. Toddy yield per tree (li) per month of 4 coconut populations at PCA-ZRC, 2000 